\title{
Correlation of urinary markers versus blood biomarkers in osteoporotic fractures
}

\author{
Ganesan Ganesan Ram ${ }^{1, *}$, P.V. Vijayaraghavan ${ }^{2}$ \\ ${ }^{\mathbf{1}}$ Associate Professor, ${ }^{2}$ Professor, Dept. of Orthopaedics, Sri Ramachandra Medical Collage, \\ Porur, Chennai, Tamil Nadu, India \\ *Corresponding Author: \\ Email: ganesangram@yahoo.com
}

\begin{abstract}
Introduction: Little has been published on the biochemical changes that can cause or a predisposing factor for osteoporotic fracture. The aim of the study is to assess whether there is any correlation of fracture to the level of serum parathyroid hormone, serum vitamin D and urinary $n$ telopeptide.

Materials and Methods: Prospective study done at Sri Ramachandra Institute of Medical Science, Chennai between October 2015 to October 2017. The Inclusion criteria were persons above 50 years of age and the patients above 50 who comes within 24 hrs following trivial fall fractures. All patients who participated in the study underwent Dexa scan for diagnosis of osteoporosis, urinary $\mathrm{n}$ telopeptide and biochemical tests like serum calcium, serum phosphate, Alkaline phosphatase, 25-hydroxy vitamin D and serum parathyroid. The patients were divided into two groups. Group I had patients without fracture and Group II had patients who had osteoporotic fractures.

Results: We had nearly twenty one pertrochantric fractures patients followed by sixteen distal radius patients. The mean value of urinary $\mathrm{n}$ telopeptide was 55.7 in group I and 186.39 in group II. The mean value of serum PTH was 69.5 in group I and 72.9 in group II.

Conclusion: Urinary marker correlates well with the osteoporotic fracture and will be a better diagnostic tool than the blood biomarkers of osteoporosis.
\end{abstract}

Keywords: Osteoporosis, Fracture, Urinary telopeptide, Serum Parathormone, Serum Alkaline phosphatase.

\section{Introduction}

Osteoporosis is a condition of decreased bone mass, leading to bone fragility and an increased susceptibility to fractures. One in three women and one in five men aged over 50 will experience osteoporotic fractures. ${ }^{1,2}$ Little has been published on the biochemical changes that can cause or a predisposing factor for osteoporotic fracture. Some of the biochemical test that are considered to be correlating to osteoporotic fracture are serum calcium, serum phosphorus, Alkaline phosphatase, 25 hydroxy vitamin D3, serum parathyroid hormone and urinary $n$ telopeptide. ${ }^{3,4}$ There are many studies pertaining to osteoporosis to serum calcium, phosphorus. The aim of the study is to assess whether there is any correlation of fracture to the level of serum parathyroid hormone, Serum vitamin D and urinary $n$ telopeptide.

\section{Materials and Methods}

Prospective study done at Sri Ramachandra Institute of Medical Science, Chennai between October 2015 to October 2017. The Inclusion criteria were persons above 50 years of age and the patients above 50 who comes within $24 \mathrm{hrs}$ following trivial fall fractures. The exclusion criteria were persons having any pathological fracture, history of any illness affecting bone metabolism like renal failure, hepatic failure, active malignancy, hyperthyroidism or hyper parathyroidism and intake of any drugs known to affect bone metabolism. All patients who participated in the study underwent Dexa scan for diagnosis of osteoporosis, urinary $\mathrm{n}$ telopeptide and biochemical tests like serum calcium, serum phosphate, Alkaline phosphatase, 25-hydroxy vitamin D and serum parathyroid.

Dexa scan was done using GE healthcare Prodigy pro DEXA machine. The most important biologic factors that can affect the level of bone and urinary bone markers were diurnal and day-to-day variability in bone- forming and bone-resorbing activities. Levels of bone turnover markers were highest in the early morning and lowest in the afternoon and evening. Hence for all our patients blood was taken in early morning. Urinary sample was collected for 24 hours from 6 am to next day $6 \mathrm{am}$ in a sterile plastic container. Urine sample was analysed by Elisa technique for urinary $\mathrm{n}$ telopeptide level. Biochemical test were done at Centralised Sri Ramachandra laboratory in our medical centre.

SRMC ethics committee clearance was obtained before the case collection. We had 110 persons participated in the study. The patients were divided into two groups. Group I had patients without fracture and Group II had patients who had osteoporotic fractures. Patients who sustained fracture from fall from standing height were only included. The collected data were analysed with IBM.SPSS statistics software 23.0 Version. To find the significant difference between the bivariate samples in Independent groups the unpaired sample t-test was used. In both the above statistical tools the probability value .05 is considered as significant level. 


\section{Results}

We had fifty-four persons in Group I and fifty six in Group II. The distribution of osteoporotic fractures patients involved in the study was tabulated in table 1 . We had nearly twenty one pertrochantric fractures patients followed by sixteen distal radius patients. The mean value of urinary $\mathrm{n}$ telopeptide was 55.7 in group I and 186.39 in group II. The mean results of urinary $n$ telopeptide, 25 hydroxy vitamin D3, serum parathormone and alkaline phosphatase were tabulated in table 2.

\section{Discussion}

There were various urinary and blood biochemical markers available for diagnosing, treatment and screening of osteoporosis and its main complication fractures. Most of these biochemical markers were mainly non-invasive, cheap. Serum calcium, serum phosphorus, serum albumin, serum Parathormone, serum alkaline phosphatase, vitamin D3, urinary $n$ telopeptide, serum $\mathrm{n}$ telopeptide, hydroxyproline were some of the biochemical markers which has direct or indirect relationship to bone metabolism osteoporosis and fracture. These biochemical markers were considered superior as any change in bone metabolism can cause a significant variation in its blood or urine values. ${ }^{5,6}$

$\mathrm{N}$ - Telopeptide (NTx) was a stable end product of bone resorption which can be found in both serum and urine. Since urinary excretion can't be affected by diet it was included into the study. ${ }^{7}$ In normal adults, about half the alkaline phosphatase in the serum comes from bone. ${ }^{8} 1,25$-dihydroxy vitamin $\mathrm{D}$ is the most potent vitamin D metabolite, levels of the $25-\mathrm{OH}$ forms of vitamin D more accurately reflect the body's vitamin D stores. Consequently, 25HDN/25-Hydroxyvitamin D2 and D3, Serum is the preferred initial test for assessing vitamin D status. However, in the presence of renal disease, 1, 25-dihydroxy vitamin D levels may be needed to adequately assess vitamin D status. ${ }^{9}$ Serum parathormone was considered to play an important role in maintaining calcium metabolism and homeostasis directly or indirectly causing osteoporosis.

From table 3 the statistical analysis clearly point out that there is no correlation of fracture to the level of serum vitamin D3 $(25 \mathrm{OH})$, serum parathormone and serum bone alkaline phosphatase. While the level of urinary $\mathrm{n}$ telopeptide has positive correlation with fracture. The drawback of this study were small sample size and only few blood biomarkers and only one urinary marker were used for analysis.

Table 1: Osteoporotic fracture and its distribution

\begin{tabular}{|l|c|c|}
\hline Fractured Part & Number & Percentage \\
\hline $\begin{array}{l}\text { Proximal } \\
\text { Humerus }\end{array}$ & 12 & 21.5 \\
\hline Distal Radius & 16 & 28.5 \\
\hline Spinal vertebra & 7 & 12.6 \\
\hline Neck of femur & 10 & 17.8 \\
\hline Intertrochantric & 11 & 19.6 \\
\hline
\end{tabular}

Table 2: T-Test Group Statistics

\begin{tabular}{|l|c|c|c|c|c|}
\hline Parameters & Group & N & Mean & Std. Deviation & Std. Error Mean \\
\hline \multirow{2}{*}{ Ntx } & I & 54 & 55.70 & 49.086 & 6.680 \\
\cline { 2 - 6 } & II & 56 & 186.39 & 161.830 & 21.625 \\
\hline \multirow{2}{*}{ Vit D $(25 \mathrm{OH})$} & I & 54 & 26.096 & 29.0762 & 3.9568 \\
\cline { 2 - 6 } & II & 56 & 19.855 & 13.2439 & 1.7698 \\
\hline \multirow{2}{*}{ Serum PTH } & I & 54 & 69.511 & 52.9988 & 7.2122 \\
\cline { 2 - 6 } & II & 56 & 72.973 & 57.8770 & 7.7341 \\
\hline $\begin{array}{l}\text { Alkaline } \\
\text { Phosphatase }\end{array}$ & I & 54 & 95.07 & 52.800 & 7.185 \\
\cline { 2 - 6 } & II & 56 & 101.59 & 67.545 & 9.026 \\
\hline
\end{tabular}

Table 3: Independent Samples Test

\begin{tabular}{|l|c|c|c|c|c|}
\hline \multirow{2}{*}{ Parameters } & \multicolumn{5}{|c|}{ t-test for Equality of Means } \\
\cline { 2 - 6 } & $\mathbf{t}$ & $\mathbf{d f}$ & Sig. (2-tailed) & Mean Difference & Std. Error Difference \\
\hline Ntx & -5.687 & 108 & .000 & -130.689 & 22.981 \\
\hline Vit D (25 OH) & 1.457 & 108 & .148 & 6.2409 & 4.2826 \\
\hline Serum PTH & -.327 & 108 & .744 & -3.4621 & 10.5922 \\
\hline $\begin{array}{l}\text { Alkaline } \\
\text { Phosphatase }\end{array}$ & -.562 & 108 & .575 & -6.515 & 11.588 \\
\hline
\end{tabular}

\section{Conclusion}

Urinary marker i.e urinary $\mathrm{n}$ telopeptide correlates well with the osteoporotic fracture and will be a better diagnostic tool than the blood biomarkers of osteoporosis.

\section{References}

1. Melton LJ, 3rd, Chrischilles EA, Cooper C, et al. (1992) Perspective. How many women have osteoporosis? J Bone Miner Res 7:1005. 
2. Kanis JA, Johnell O, Oden A, et al. (2000) Long-term risk of osteoporotic fracture in Malmo. Osteoporos Int 11:669.

3. Reid IR, Bolland MJ, Grey A. Effect of calcium supplementation on hip fractures. Osteoporos Int 2008; 19:1119-23.

4. Hanley DA, Cranney A, Jones G, et al. Vitamin D in adult health and disease: a review and guideline statement from Osteoporosis Canada. CMAJ 2010; 182:E610-8.

5. Delmas PD. Biochemical markers of bone turnover: Methodology and clinical use in osteoporosis. Am J Med (Supp. 5B) 1991;91:59S-63S.

6. Eyre DR. New biomarkers of bone resorption (editorial). J Clin Endocrinol Metab 1992; 74:470A470C.

7. Jayaram N, Bijoor AR, Rajagopalan N, Venkatesh T. The value of serum and urinary $n$-Telopeptide in the diagnosis of osteoporosis. Indian J Orthop 2002;36:9.

8. Calvo MS, Eyre DR, Gundberg CM. Molecular basis and clinical application of biological markers of bone turnover. Endocr Rev 1996;17:333-368.

9. Bringhurst FR, Demay MB, Kronenberg HM: Vitamin D (calciferols): metabolism of vitamin D. In Williams Textbook of Endocrinology. Ninth edition. Edited by JD Wilson, DW Foster, HM Kronenberg, PR Larsen. Philadelphia, WB Saunders Company, 1998, pp.11661169. 